Scientific Journal of Hamadan Nursing \& Midwifery Faculty - ISSN 2008-2800

\title{
The Effectiveness of Participation in Recreational-Sport Activities on Quality of Life in Women with Schizophrenia
}

\author{
Mitra Fakhraee Aghdam ${ }^{1}$, Anahita Khodabakhshi-Koolaee ${ }^{2 *}$, Mahnaz Khatiban ${ }^{3}$
}

1. MSc, Department of Counseling, Faculty of Humanities, Islamic Azad University, Branch Of Central, Tehran, Iran

2. Assistant Professor, Department of Psychology \& Education, Faculty of Humanities, Khatam University, Tehran, Iran

3. Associate Professor, Mother \& Child Care Research Center, Hamadan University of Medical Sciences, Hamadan, Iran

\begin{tabular}{lr}
\hline \multicolumn{2}{c}{ Article Info } \\
\hline & \\
Received: & $2017 / 04 / 3$ \\
Accepted: & $2017 / 07 / 3$ \\
Published Online & $2017 / 07 / 17$
\end{tabular}

DOI:

Original Article

Use your device to scan and read the article online

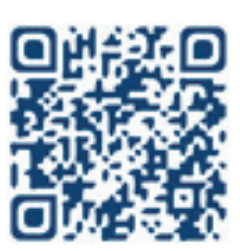

\section{Abstract}

Introduction: A lot of people who suffer from psychological diseases declare how physical activities play a significant role in various aspects of quality of life. This study was aimed to investigate the effects of the participation of women with Schizophrenia in recreational and physical activities.

Methods: Research design was Semi-experimental. The statistical society consisted of all women referred to Razi psychiatric hospital in 2015. Among them 24 were selected by purposive sampling and were divided into two groups (12 experimental and 12 control). Experimental group received 12 sessions of recreational physical activity, 3 times a week. Research instruments was Quality of Life Questionnaire which has four sub-scales of public health, environmental health, mental health and physical health and were performed pre-test and post-test. The data was analyzed using univariate and multivariate analysis of covariance and SPSS23.

Results: According to the findings there was a significant difference between the two groups in the total score of quality of life $(\mathrm{F}=91.82$, sig=0.001). Moreover, the significant difference has been indicated in sub-scales of questionnaire like; physical health $(\mathrm{F}=34.39$, sig $=0.001)$, mental health $(\mathrm{F}=27.24$, sig=0.001 $)$, social health $(\mathrm{F}=59.63$, sig=0.001), and environmental health $(\mathrm{F}=80.81$, sig=0.001).

Conclusion: The results showed that Participation in recreational sports activities, improves quality of life in people with chronic mental disorders. In Addition, participation in Physical - recreational activities leads to increased physical, mental, social and environmental health of these patients.

Keywords: Recreational-Sport Activity; Quality of Life; Schizophrenia.

Copyright $(C)$ 2017, Sci J Hamadan Nurs Midwifery Fac. This is an open-access article distributed under the terms of the Creative Commons Attribution-noncommercial 4.0 International License which permits copy and redistribute the material just in noncommercial usages, provided the original work is properly cited.

How to Cite This Article:

Fakhraee Aghdam M, Khodabakhshi-Koolaee A, Khatiban M. The Effectiveness of Participation in Recreational-Sport Activities on Quality of Life in Women with Schizophrenia. Sci J Hamadan Nurs Midwifery Fac. 2017; 25 (4) 


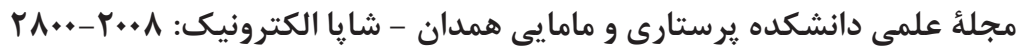 مقالأ يزوهشى \\ اثربخشى مشاركت در فعاليتهاى گروهى ورزشى ـ تفريحى بر كيفيت زندكى بيماران زن اسكيزوفرنى}

\section{ميترا فخر ايى اقدم'، آناهيتا خدابخشى كولايى'، مهناز خطيبانَr}

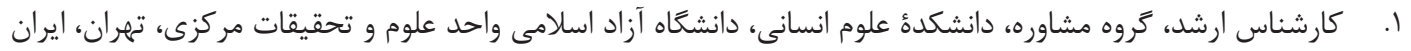

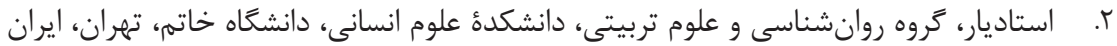

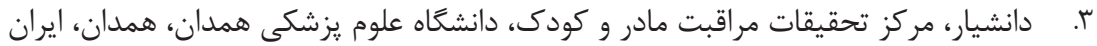

\begin{tabular}{|c|c|}
\hline جكيده & اطلاعات مقاله \\
\hline 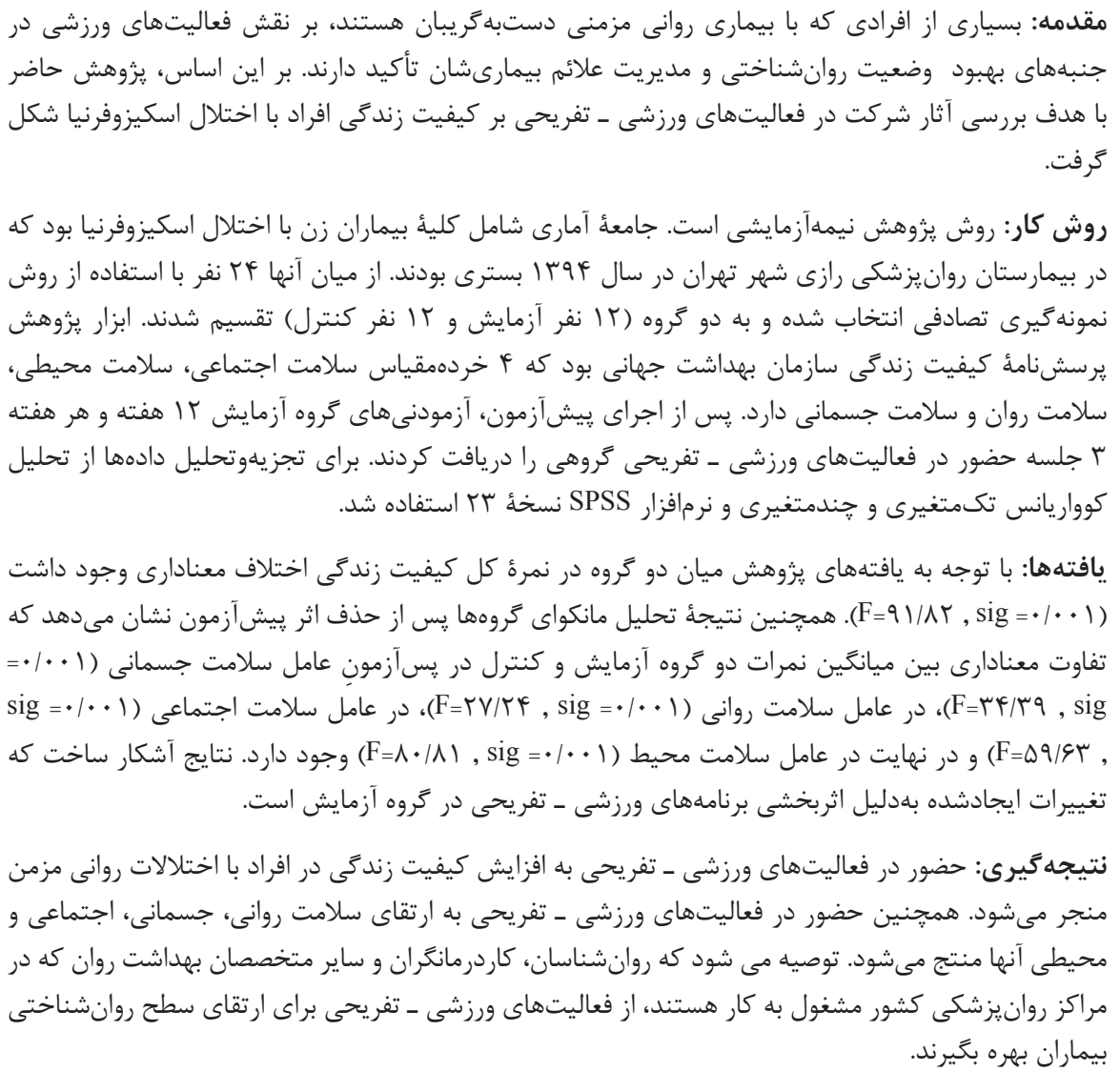 & 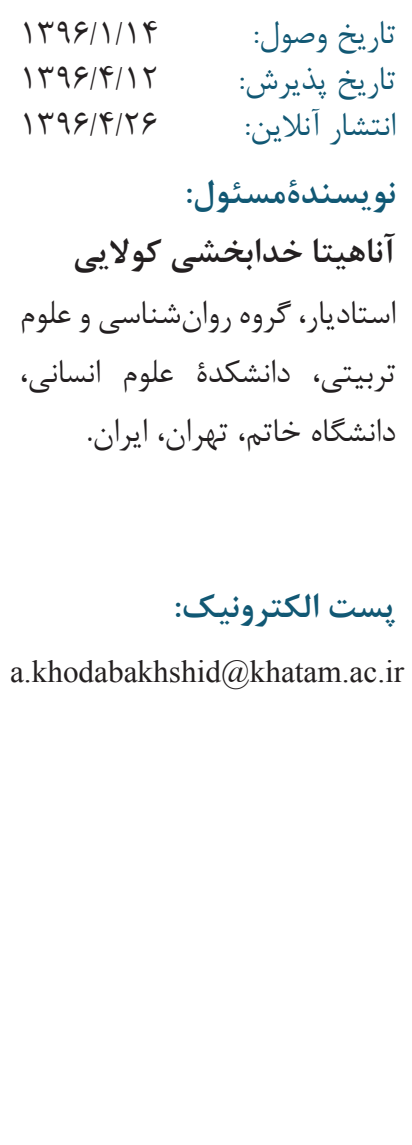 \\
\hline وازههاى كليدى: فعاليتهاى تفريحى ورزش & \\
\hline
\end{tabular}


در واقع ورزش بهعنوان يك ركن اساسى شيوه زندكى سالم

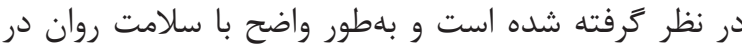

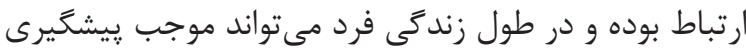

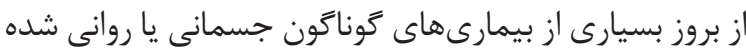

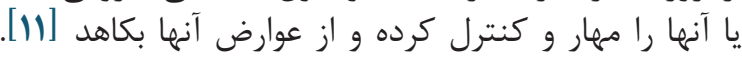

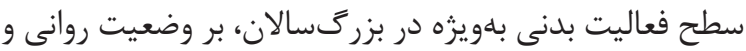

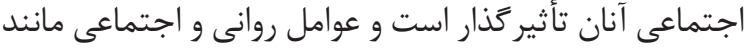

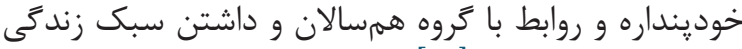

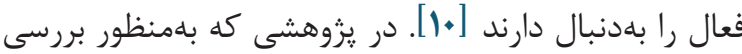

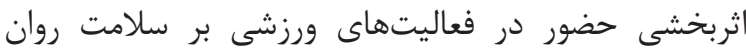

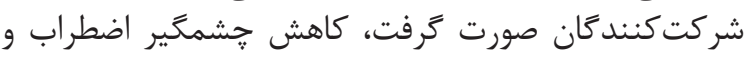

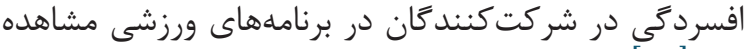

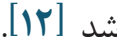

Boyera

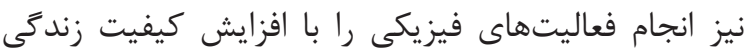

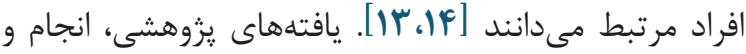

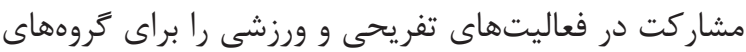

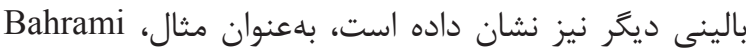
Einolgasi

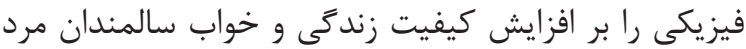

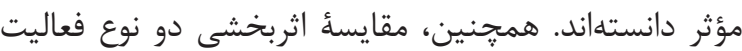

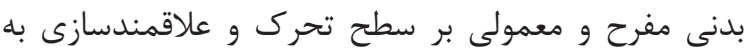

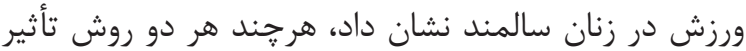

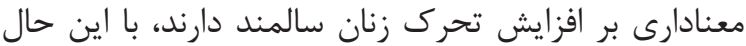

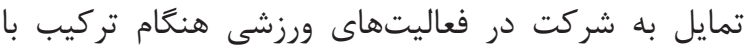

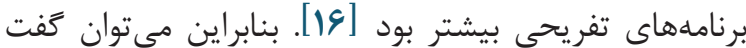

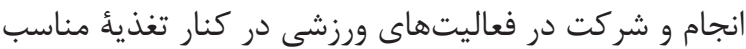

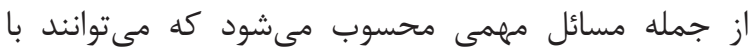

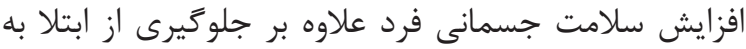

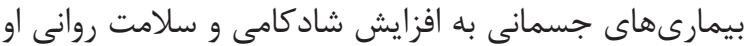

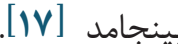

با اين حال، بيشتر شواهد يزوهشى در زمينأ برنامههاى

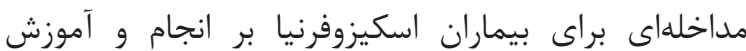

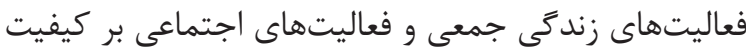

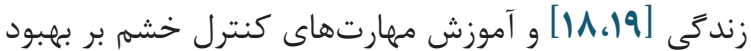

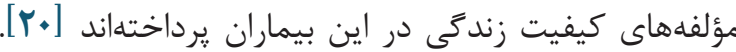
با اين حال بايد بلهخاطر داشت، هرجند فعاليتهاى

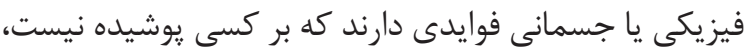

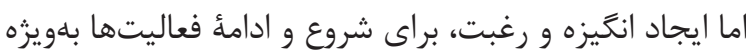

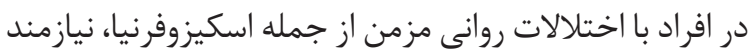

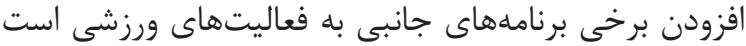

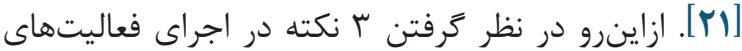

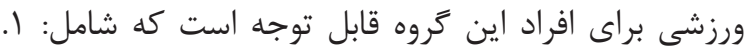

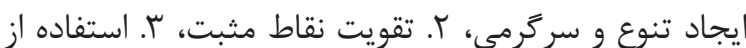

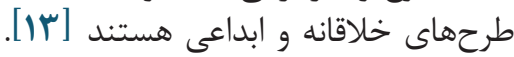

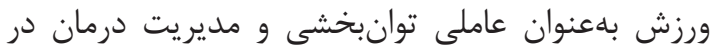

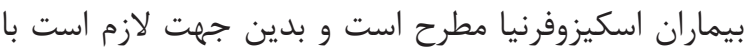

مقدمه

اسكيزوفرنيا، يكى از ناتوان كنندهترين بيمارىهاى سيستم

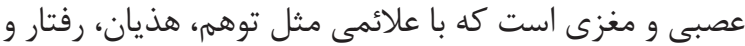

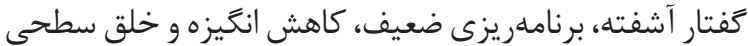

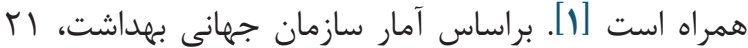

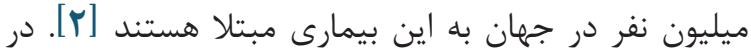

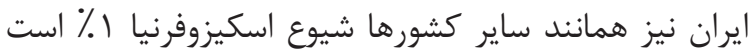

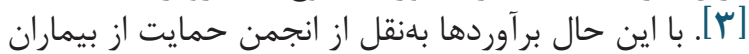

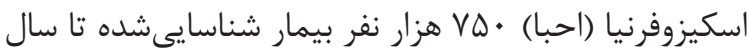

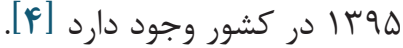

يكى از مشكلاتى كه اين اختلال بههمراه دارد، كاهش

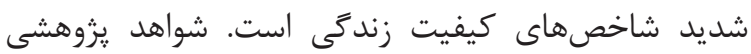

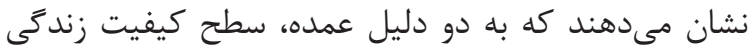

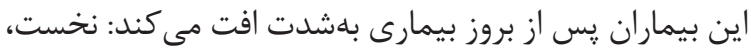

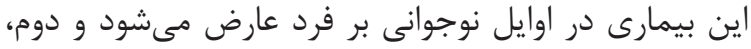

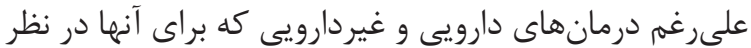

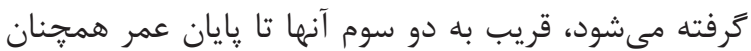

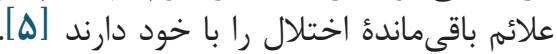
در اين ميان، بنابر يزوهشهاى انجامشده، ابتلاى افراد

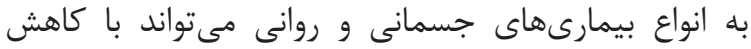

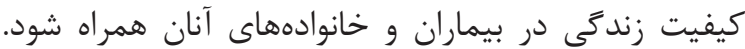

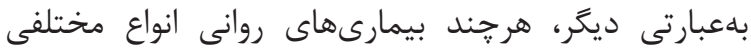

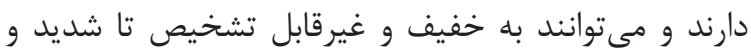

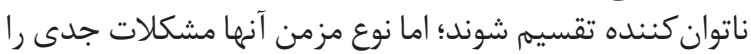

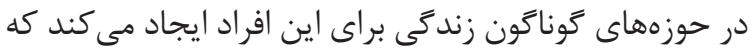

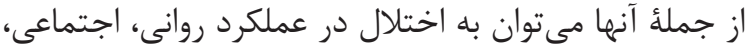

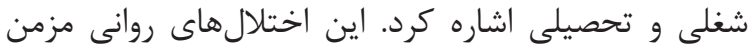

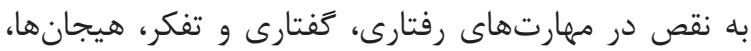

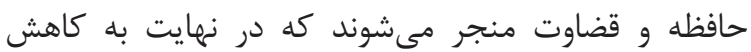
كيفيت زندگى اين افراد مى انجامد [G،V]

از طرفى، براساس تعريف سازمان بهداشت جهانى،

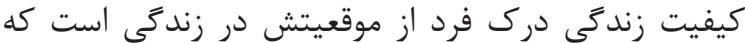

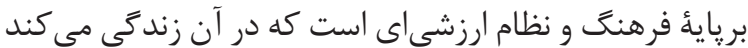

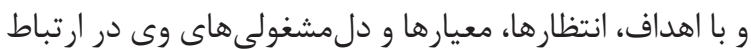

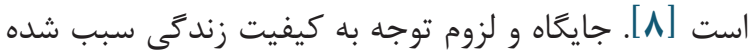

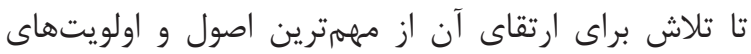

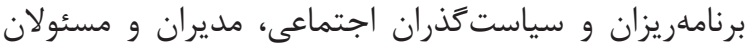

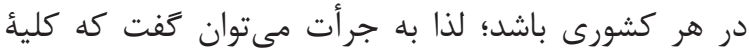

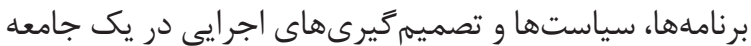

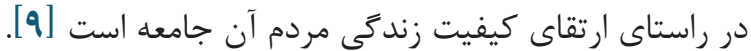

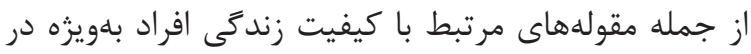

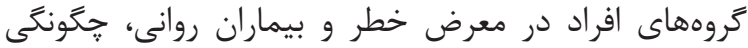

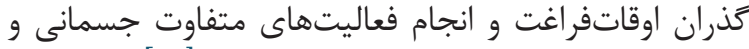

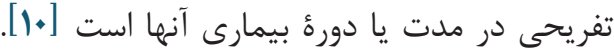
در تعاريف سازمان بهداشت جهانى از مفهوم سلامت نيز

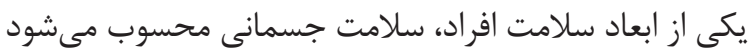

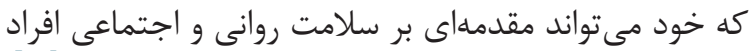

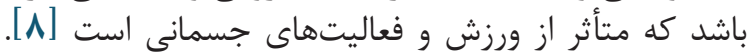


همززمان تحت مداخلهُ ورزشى ـ تفريحى و يا روانشناختى

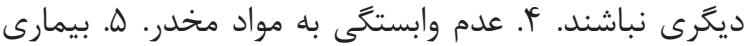

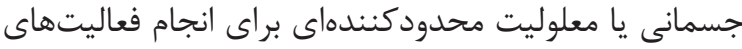
ورزشى نداشته باشند.

معيارهاى خروج از يزوهش شامل: ا. غيبت بيش از سه

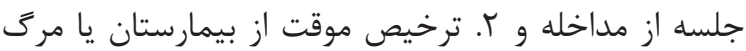

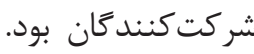

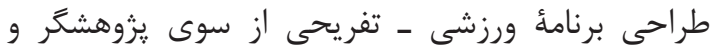

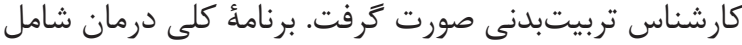

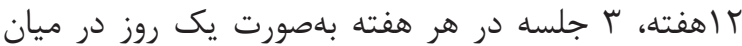

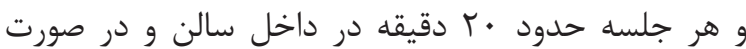

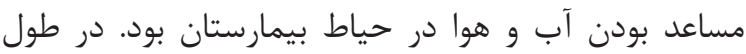

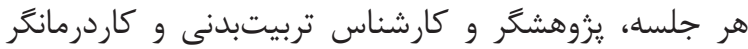

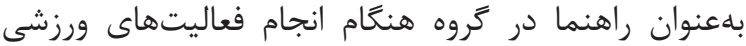

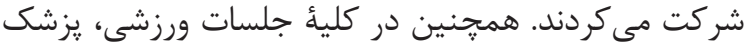

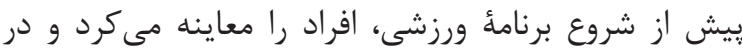

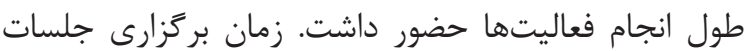

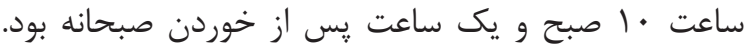

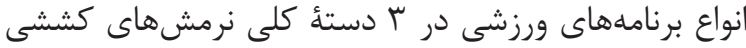

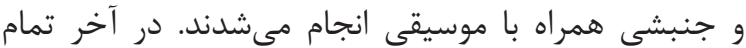

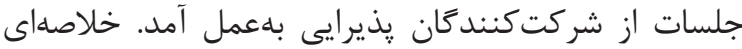

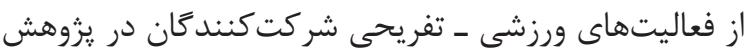

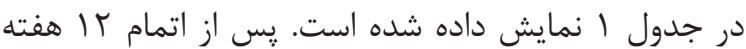

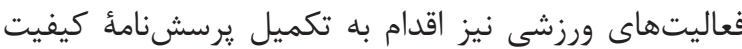

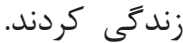

براى جمع آورى دادههاى اين يزوهش از يرسشنامئ

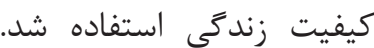

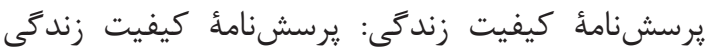

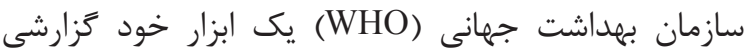

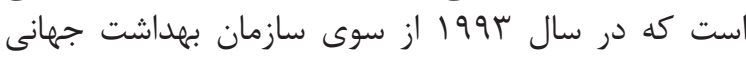

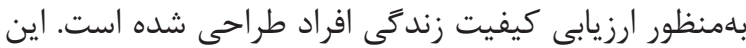

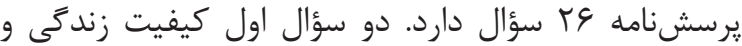

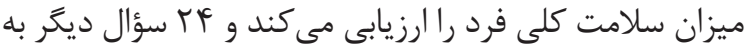

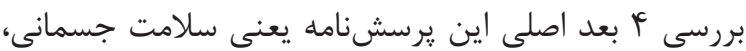

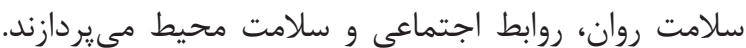

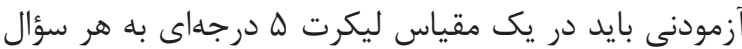

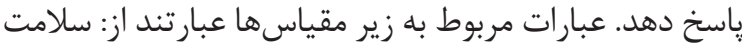

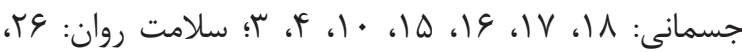

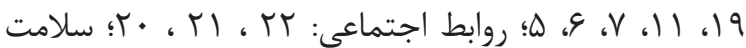

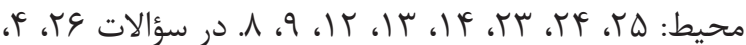

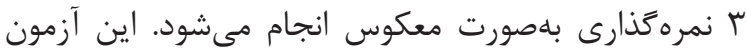

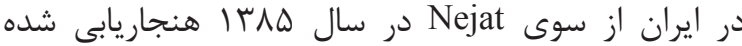

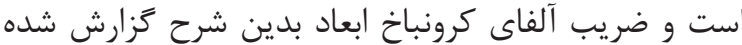

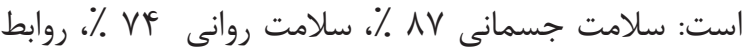

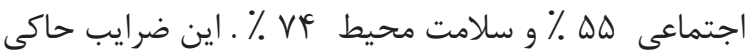

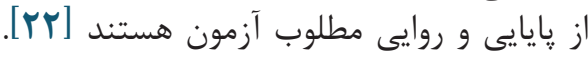

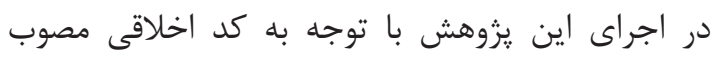

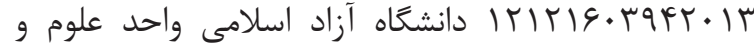

ساير فعاليتهاى تفريحى و اجتماعى تركيب شود. زيرا به إنه

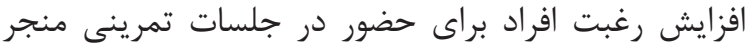

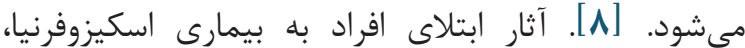

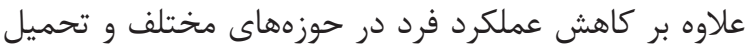

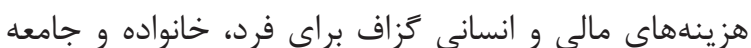

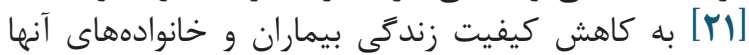
منجر خواهد شد.

كرجه، اثربخشى فعاليتهاى ورزشى بر كروههاى ديكر

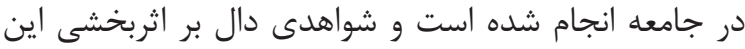

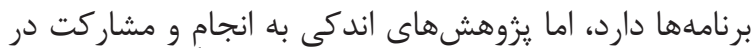

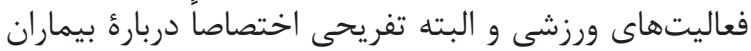

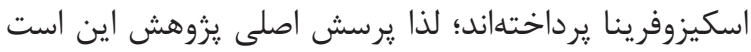

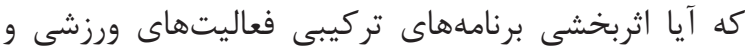

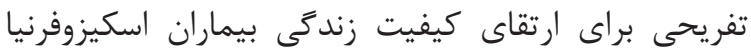

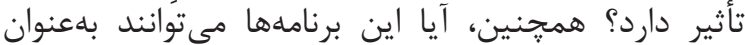

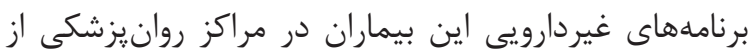
سوى متخصصان بهداشت روان و و سلامت استفاده شوند؟

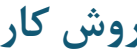

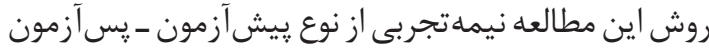

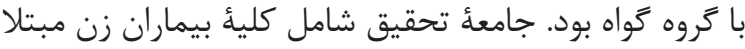

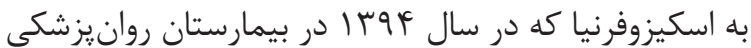

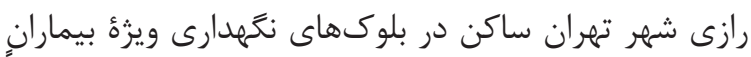

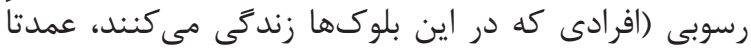

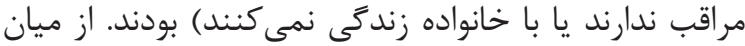

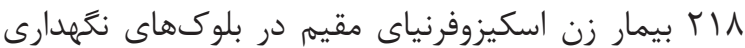

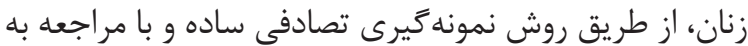

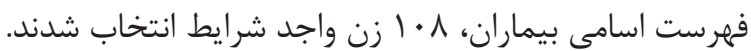

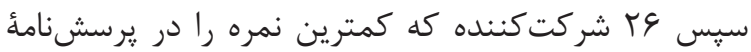

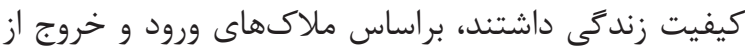

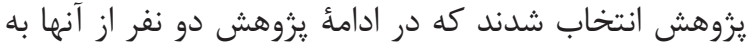

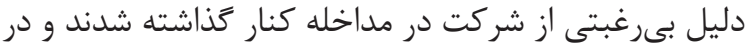

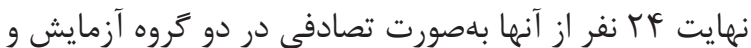

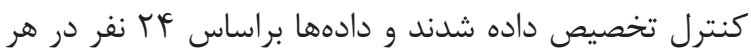

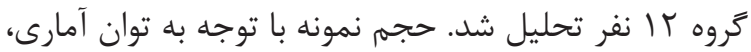

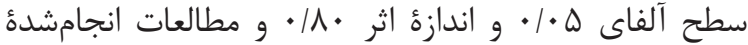

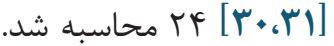

معيارهاى ورود به يزروهش عبارتند از: 1. تشخيص

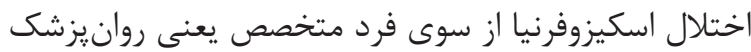

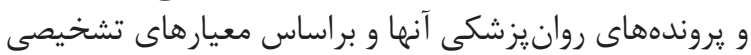
سيكل DSM-V

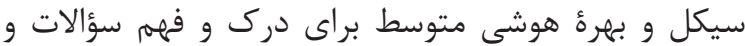

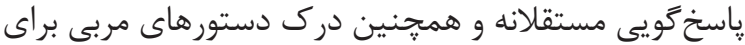

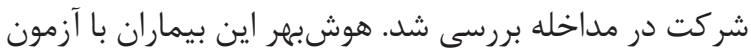

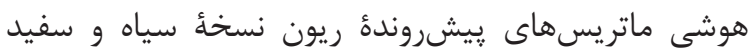

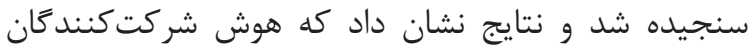

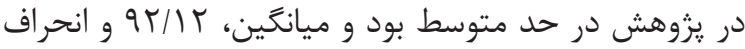

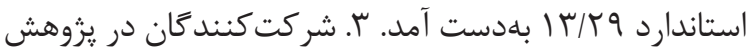




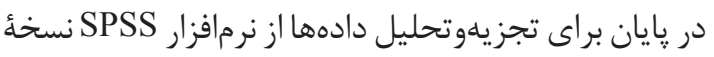

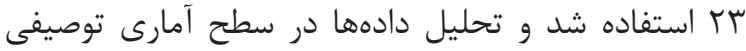

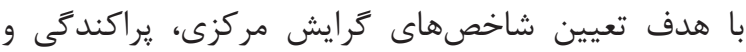

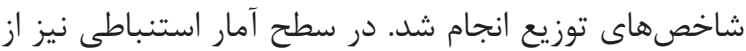

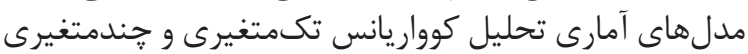

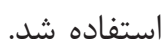

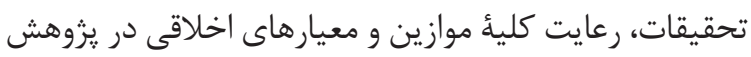

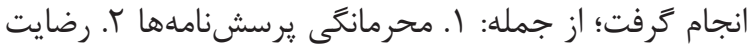

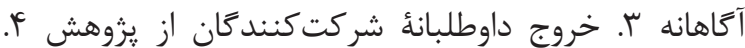

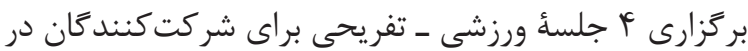

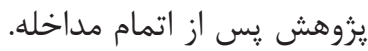

جدول ا. خلاصةُ جلسات مداخله برنامههاى ورزشى ـ تفريحى

اتجام حركات كششى و نرمش - ريلكسيشن در حالت خوابيده با حشمان بسته و دم و بازدم عميق ـ رقص و انجام حركات موزون با موزيك

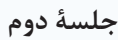

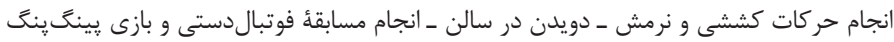

جلسؤ سوم

انجام حركات كششى و نرمش ـ دويدن در زمين جمن ـ بركزارى مسابقه دارت ـ پِّ از اتمام مسابقه، به بيماران بلعنوان جايزه شير و كيك داده شد.

جلسؤ جهارم

انجام حركات كششى و نرمش ـ بازى وسطى ـ تمرين ريلكسيشن در حالت خوابيده

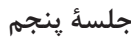

انجام حركات كششى و نرمش ـ راه رفتن روى تردميل ـ پپى از آن مددجويان دارت بازى كردند.

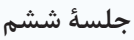

انجام حركات كششى و نرمش ـ دويدن در سالن بهطور دستهجمعى ـ انجام بازى فوتبالدستى، تنيسروىميز و بدمينتون

جلسةٔ هفتم

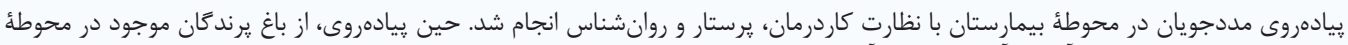

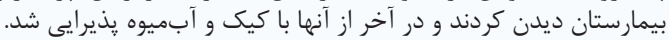

انجام حركات كششى و نرمش ـ آغاز پِيادروى ـ سِّ ير تاب توٍ بسكتبال در تور ـ كوش دادن به موسيقى و اجراى حركات موزون

جلسؤ هشتم

$$
\text { (2) }
$$

كرَدش و يِيادروى در محوطؤ بيمارستان انجام شد. سيس به فروشعاه بيمارستان برده شدند تا خوراكى خريدارى كنند.

جلسئ نهم

جلسهٔ دهم

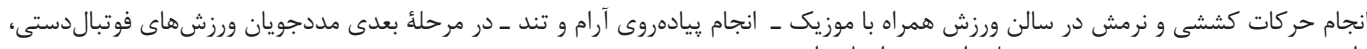

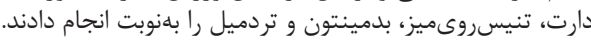

جلسهٔ يازدهم

انجام ورزشهاى كششى و نرمش ـ حركات موزون همراه با موسيقى ـ انجام بازى وسطى بلصورت كروهى

جلسئ دوازدهم

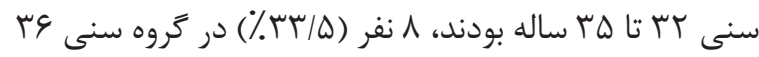

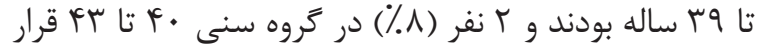

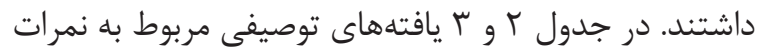

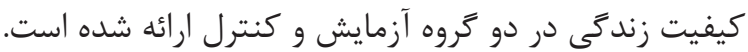

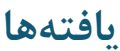

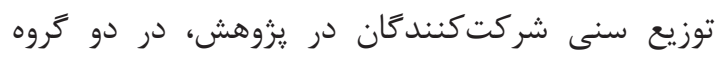

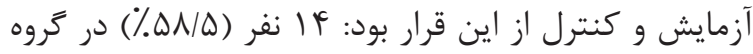

جدول r. يافته هاى توصيفى كيفيت زندكى در كروه آزمايش

\begin{tabular}{|c|c|c|c|c|c|c|}
\hline ضريب كشيدَّى & ضريب كجى & انحراف استاندارد & ميانًَين & ت تعداد & سطح & متغير \\
\hline .191 & ./1 & $1 / 19$ & $\mid \Delta / \kappa^{k}$ & ir & يِشآزمون & \multirow{2}{*}{ سلامت جسمانى } \\
\hline$-\cdot / \wedge V$ & $\cdot 1 \cdot \Delta$ & $1 / 91$ & $1 / / 9$. & ir & يس آزمون & \\
\hline$-\cdot N \Delta$ & $\cdot \pi V$ & $r / \cdot 1$ & $\mid Q / 9$. & ir & ِيشآزمون & \multirow{2}{*}{ سلامت روان } \\
\hline$-\cdot / \mu$ & $-\cdot / \Delta \Delta$ & $r / \pi)$ & $\mid N / V$ & ir & يَى آزمون & \\
\hline$\cdot / \cdot r$ & $\cdot N r$ & $1 / \Delta T$ & 911. & ir & پِيشآزمون & \multirow{2}{*}{ روابط اجتماعى } \\
\hline 吾 & -.1 .9 & $1 / 4 F$ & N/9. & ir & يس آزمون & \\
\hline$-\cdot \mid \Delta r$ & $\cdot 1 \cdot 1$ & $r / I V$ & $r r / Q$. & ir & يِشآزمون & \multirow{2}{*}{ سلامت محيط } \\
\hline$-\cdot / \Delta 9$ & $\cdot|4|$ & $1 / 1 \Lambda$ & re/V. & ir & يس آزمون & \\
\hline$-\cdot 1 \Delta 9$ & $\cdot|4|$ & $r / T V$ & $9 \cdot 19$. & ir & بِيشآزمون & \multirow{2}{*}{ كيفيت زندَّى } \\
\hline .194 &.$- / 99$ & T/ब & $V T / 9$. & ir & يسىآزمون & \\
\hline
\end{tabular}


جدول r. يافتههاى توصيفى كيفيت زندكى در تروه كنترل

\begin{tabular}{|c|c|c|c|c|c|c|}
\hline ضريب كشيدَّى & ضريب كجى & انحراف استاندارد & ميانغين & ت تعداد & سطح & متغير \\
\hline 1/1r & $\cdot / K r$ & $r / 9 \Delta$ & $1 \% / \lambda$. & ir & يِيش آزمون & \multirow{2}{*}{ سلامت جسمانى } \\
\hline - & $-\cdot / V r$ & r & $1 f / V$. & ir & يس آزمون & \\
\hline$-1 / \cdot 1$ &.$/ 1 r$ & $\tau / \cdot \Delta$ & $19 / \mathrm{V}$ & ir & پيش آزمون & \multirow{2}{*}{ سلامت روان } \\
\hline$-\cdot / \wedge$ & $\cdot 1 \Delta \Delta$ & $r / \cdot 9$ & $\mid g / 4$. & ir & هِ آزمون & \\
\hline $.1 \cdot r$ & $\cdot / Q F$ & $1 / \pi 4$ & $\Delta / 4$. & ir & ِيش آزمون & \multirow{2}{*}{ روابط اجتماعى } \\
\hline$-\cdot 119$ & $\cdot|r|$ & I/FT & $\Delta / 9$. & ir & يس آزمون & \\
\hline.$- \mid 94$ & $\cdot \pi v$ & $r / 4 q$ & r & ir & بيش آزمون & \multirow{2}{*}{ سلامت محيط } \\
\hline-.190 &.$- / . q$ & $r / 91$ & $T T / V$. & ir & يس آزمون & \\
\hline$-\cdot / \Lambda V$ & $-\cdot 119$ & שת/r & $q \cdot / 4$. & ir & ِيش آزمون & \multirow{2}{*}{ كيفيت زندكى } \\
\hline$-\cdot / \mathrm{VV}$ &.$- / 11$ & f/9V & $\Delta q / 4$. & ir & يس آزمون & \\
\hline
\end{tabular}

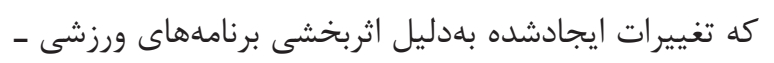

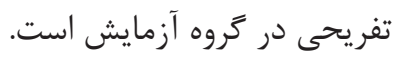

براى بررسى اثربخشى مداخله بر مؤلفههاى كيفيت

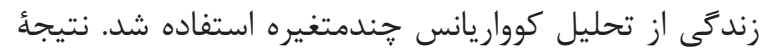

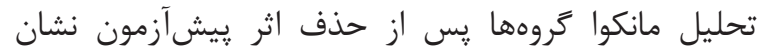

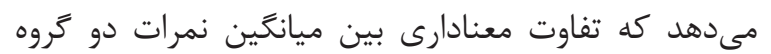

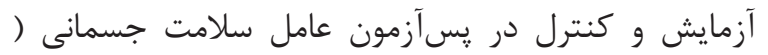

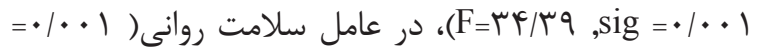

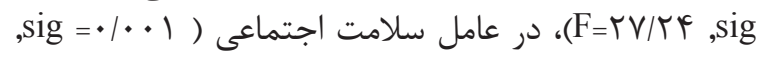

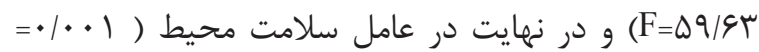

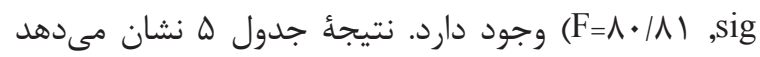

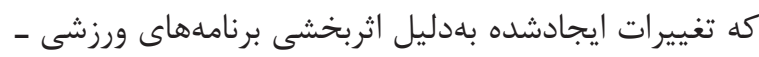

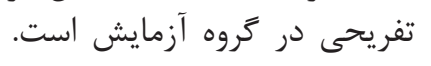

يس از جمعآورى دادهها ابتدا ييشفرضهاى آزمون آنكوا

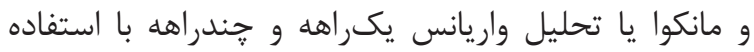

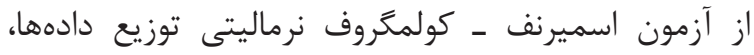

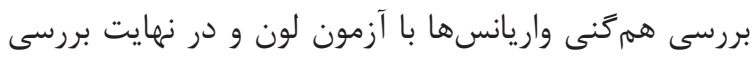

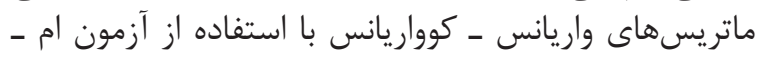

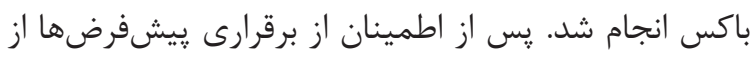

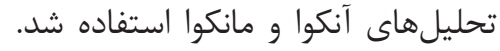

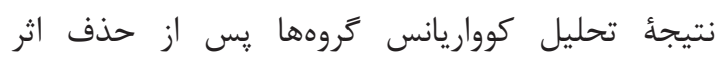
ييشآزمون نشان مىدهد كه تفاوت معنادارى بين ميانكين

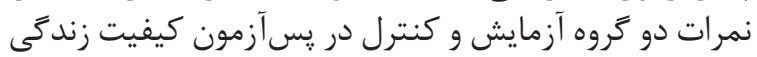
(نمره كلى) وجود دارد.

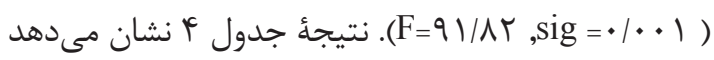

$$
\text { جدول F. تحليل كوواريانس مرتبط با تأثير فعاليتهاى ورزشى بر كيفيت زندكى }
$$

\begin{tabular}{|c|c|c|c|c|c|}
\hline سطح معنادارى & $\mathbf{F}$ & ميانكين مجذورات & درجئ آزادى & مجموع مجذورات & منبع تغييرات \\
\hline$\cdots 1 / \cdot$ & $|r| r \mid$ & $r \cdot V / r r$ & 1 & $r \cdot V / r r$ & بيش آزمون \\
\hline$\cdots 1 / \cdot$ & $\| K / \cdot r$ & MNT/AD & 1 & MNT/AD & تروه \\
\hline - & - & $\mathrm{V} / \mathrm{A \Lambda}$ & IV & (rm/ag & خطا \\
\hline
\end{tabular}

جدول ه. تحليل كوواريانس هندمتغيره مرتبط با تأثير فعاليتهاى ورزشى بر مؤلفههاى كيفيت زندكى

\begin{tabular}{|c|c|c|c|c|c|}
\hline سطح معنادارى & $\mathbf{F}$ & ميانكين مجذورات & درجهُ آزادى & مجموع مجذورات & منبع تغييرات \\
\hline$\cdots 1 / \cdot$ & $r k / r q$ & VT/GT & 1 & VT/GT & سلامت جسمانى \\
\hline$\cdots 1 / \cdot$ & TVITF & $\Delta \cdot / \Lambda F$ & 1 & $\Delta \cdot / \Lambda F$ & سلامت روان \\
\hline$\cdots 1 / \cdot$ & $r \Delta / r q$ & $\Delta 9 / 94$ & 1 & rq/बr & سلامت اجتماعى \\
\hline$\cdots 1 / \cdot$ & $Q \cdot / Q T$ & $\Lambda \cdot|\Lambda|$ & 1 & $\Lambda \cdot|\lambda|$ & سلامت محيط \\
\hline
\end{tabular}




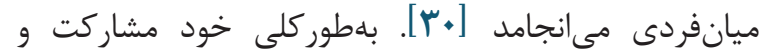

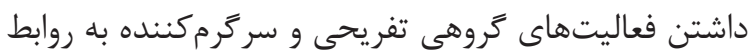

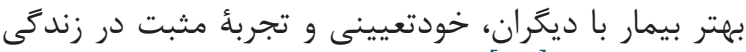

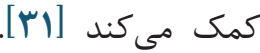

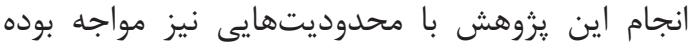

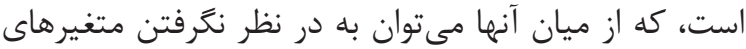

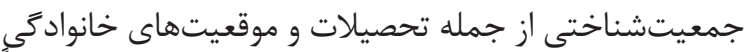

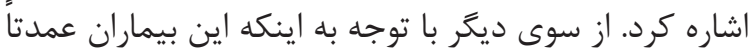

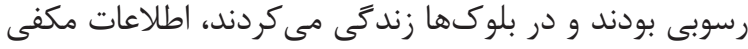

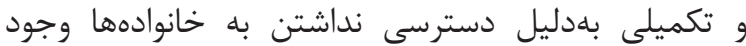
نداشت. همجنين، فقدان بردئ درسى تداوم تأثيرات مشاركت

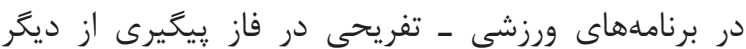

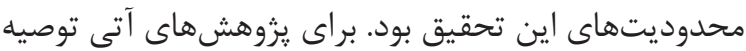

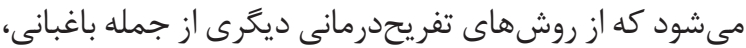

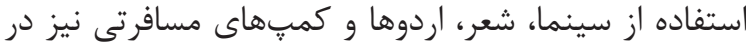

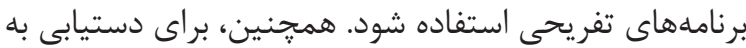

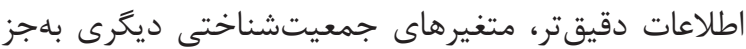

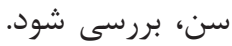

\section{نتيجهَ نيرى}

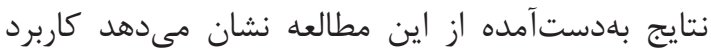

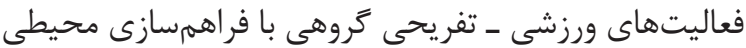

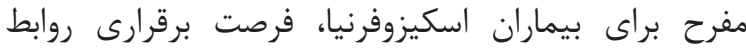

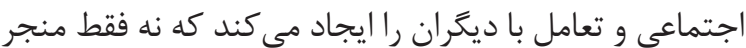

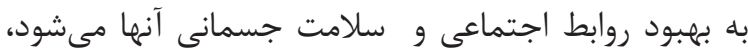

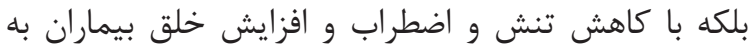

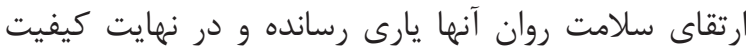

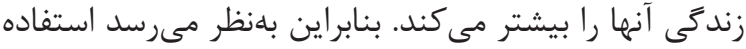

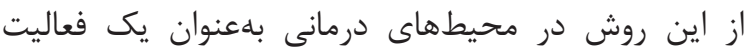

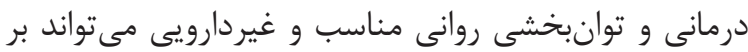

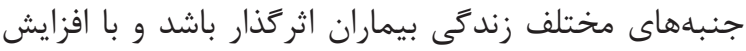

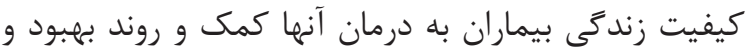

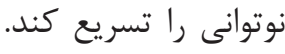

\section{سياسگزارى}

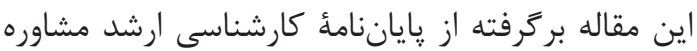

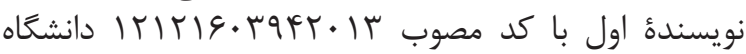

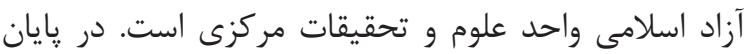

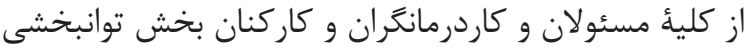

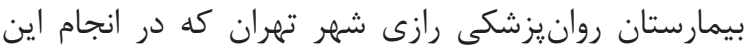

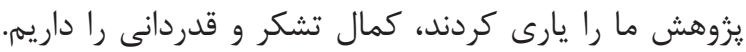

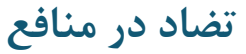

در اين مطالعه تضاد منافع وجود ندارد.

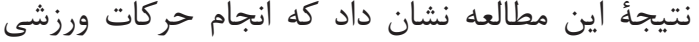

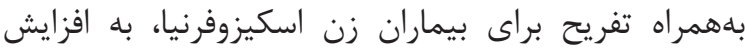

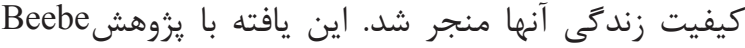

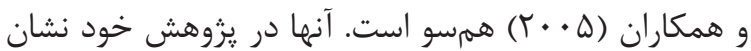

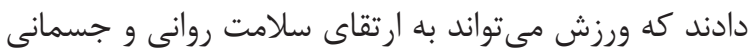

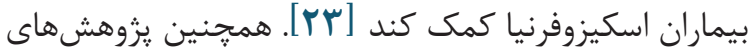

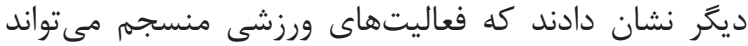

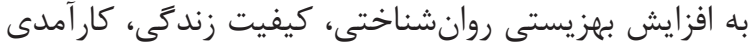

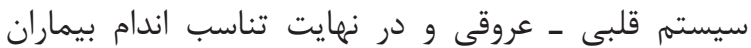

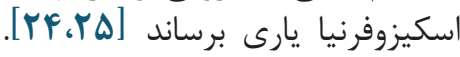

هر جند كه فعاليتهاى ورزشى براى بيماران اسكيزوفرنيا

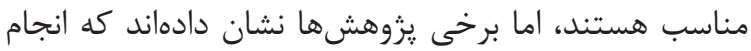

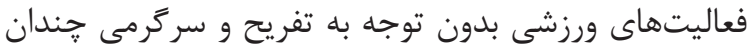

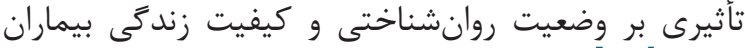

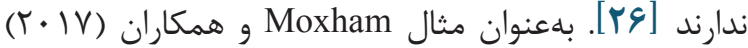

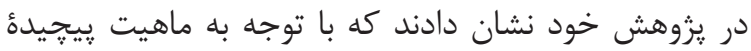

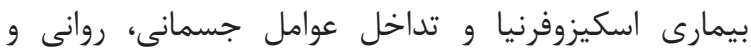

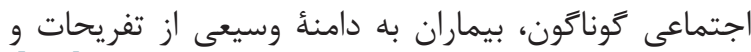

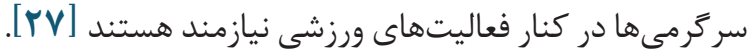
همجنين نتايج آشكار ساخت كه انجام فعاليتهاى

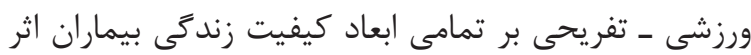

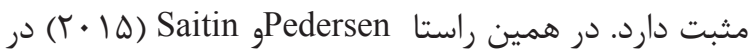

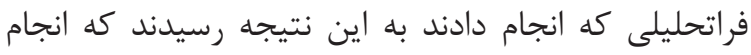

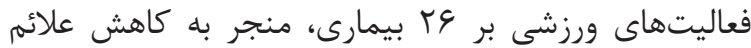

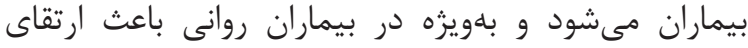

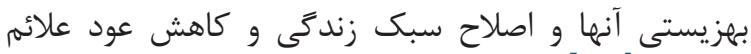

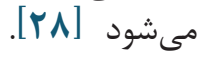
علاوه بر اين، يافتههاى مطالعاتى ديخرى نيز نشان دادهاند،

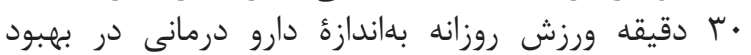

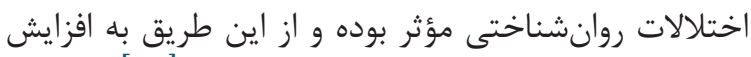

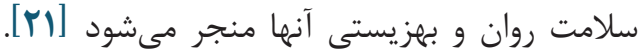
و همكاران (rار • Scheewe

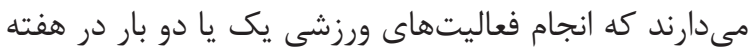

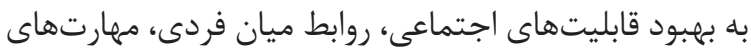

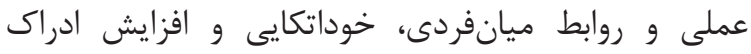

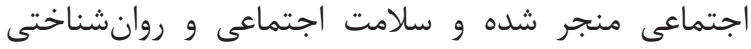

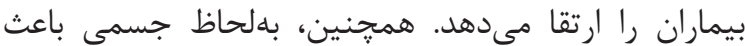

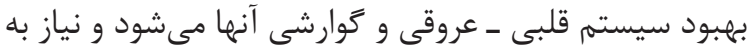

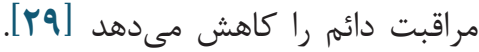
در عين حال ورزش كردن و شركت در فعاليتهاى

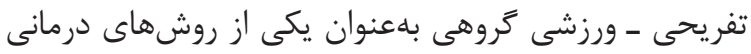

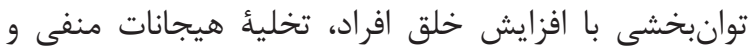

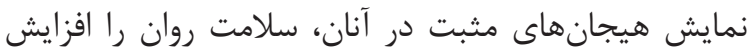

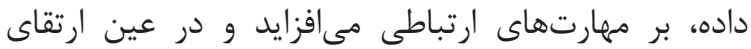

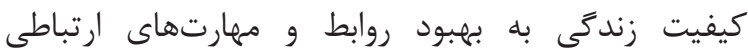




\section{References}

1. McGrath J, Saha S, Welham J, El Saadi O, MacCauley $\mathrm{C}$, et al. A systematic review of the incidence of schizophrenia: The distribution of rates and the influence of sex, urbanity, migrant status and methodology. BMC Medicine. 2004;2:13. 2. DOI: $\underline{10.1186 / 1741-7015-2-13 .}$

2. Saha S, Chant D, Welham J, and McGrath J. (2005). A Systematic Review of the Prevalence of Schizophrenia. PLoS Med. 2005 ; 2(5):e141. doi: 10.1371/journal.pmed.0020141 PMCID: PMC1140952.

3. What is Schizophrenia? http://www.who.int/ mental_health/management/schizophrenia/en/

4. The population of Schizophrenia in Iran. http:// www.isna.ir/news/95100603447/750

5. Murray CJ, Lopez AD, editors. The global burden of disease: A comprehensive assessment of mortality and disability from diseases, injuries, and risk factors in 1990 and projected to 2020. Boston: Harvard School of Public Health; 1996,PP:990.

6. Koolaee AK, Etemadi A. The outcome of family interventions for the mothers of schizophrenia patients in Iran. International Journal of Social Psychiatry. 2010;56(6):634-46. doi/ pdf/10.1177/0020764009344144

7. Callaghan P. Exercise: a neglected intervention in mental health care? Journal of Psychiatry Mental Health Nursing. 2004;11(4):476-83. DOI: $\quad 10.1111 / \mathrm{j} .1365-2850.2004 .00751 . \mathrm{x}$

8. World Health Organization. Action plan for the global strategy for the prevention and control of non-communicable diseases. Geneva, Switzerland: World Health Organization, 2013.

9. Li SG, Lu F, Wang AHH. Exploring the relationships of physical activity, emotional intelligence and health in Taiwan college students. Journal of Exercise Science and Fitness. 2009;7(1):55-63.

10. Vuillemin A, Boini S, Bertrais S, Tessier S, Oppert JM, Hercberg S, et al. Leisure time physical activity and health-related quality of life. Prevention Med. 2005;41(2):562-9. https://doi.org/10.1016/j.ypmed.2005.01.006 PMid: 15917053

11. Parker AG, Hetrick SE, Jorm AF, Yung AR, McGorry PD, Mackinnon A, Moller B, Purcell R. The effectiveness of simple psychological and exercise interventions for high prevalence mental health problems in young people: a factorial randomized controlled trial. Bio Med Central. (2011);12:76. https://doi.org/10.1186/1745$\underline{6215-12-76}$

12. Berchtold N.C, Castello N, Cotman C.W. "Exercise and time - dependent benefits to learning and memory". Neuroscience. 2010;167(3):588$97 . \quad$ https://doi.org/10.1016/j.neuroscience.2010.02.050

13. Boyera L, Baumstarcka K, Iordanovaa T, Fernandeza J, Jeanb P, Auquiera P. A. poverty-related quality of life questionnaire can help to detect health inequalities in emergency departments. Journal of Clinical Epidemiology. 2014;67(3):285-95. https://doi.org/10.1016/j. jclinepi.2013.07.021

14. Bize R, Johnson JA, Plotnikoff RC. Physical activity level and health-related quality of in the general adult population: A systematic review. Preventive Medicine. 2014;45(6):401-15. https://doi.org/10.1016/j.ypmed.2007.07.017

15. Bahrami Einolgasi H, Khodabakhshi koolaee A, Taghvaee D. Efficacy of group physical activity on sleep quality and quality of life among older adults in Kahrizak nursing home. joge. 2016;1(1):29-39. https://doi.org/10.18869/acadpub.joge.1.1.45

16. Mazllom SR., Najafi Z., Kooshyar H., \& Azhari A. Comparison of the effect of two fun and regular physical activities on the rate of activity and interest to perform exercise in older women residential in Mashhad nursing homes. IJOGI, 2015;18(162):1-10. DOI: 10.22038/ijogi.2015.4973

17. Neumark-Sztainer D, Story M, Hannan PJ, Tharp T, Rex J. Factors associated with changes in physical activity: a cohort study of inactive adolescent girls. Archives of Pediatrics \& Adolescent Medicine. 2003;57(8):803-10. https://doi. org/10.1001/archpedi.157.8.803

18. Khodabakhshi-Koolaee A, \& Falsafinejad MR. Effects of communal living Skills on improving Activities of daily living of male patients with schizophrenia, Schizophrenia Research. 2014;1(1):4-8

19. Hematimanesh A, Azkhosh M, Khodabakhshi-koolaee A., Khodaee MR. effectiveness of group training program for social skills in the improvement of daily life skills of male patients with schizophrenia. Research in rehabilitation science. 2012;8(1):113-21.

20. Khodabakhshi-Koolaee A, Ebrahim Baighi H, Navidian A. Effects of Communication Skills Training on Aggression and Quality of Life of Male Patients with Chronic Mental Illnesses. JCCNC. 2016;2 (1):3-10 URL: http://jcenc.iums. ac.ir/article-1-79-en.html

21. Sarafino EP. Smith TW. Health psychology: bio-psychosocial interactions, 8th ed. New York: Wiley; 2014.83-7. 
آناهيتا خدابخشى كولايى و همكاران. وس"

22. Nejat S, Montazeri A, Holakouie Naieni K, Mohammad K, Majdzadeh S. The World Health Organization quality of Life (WHOQOL-BREF) questionnaire: Translation and validation study of the Iranian version. sjsph. 2006;4(4):1-12. URL: http://sjsph.tums.ac.ir/article-1-187-fa. $\underline{\mathrm{html}}$

23. Beebe LH, Tian L, Morris N, Goodwin A, Allen SS, and Kuldau J. EFFECTS OF EXERCISE ON MENTAL AND PHYSICAL HEALTH PARAMETERS OF PERSONS WITH SCHIZOPHRENIA. Issues in mental health Nursing, 2005;26(6):661-7. https://doi. org/10.1080/01612840590959551

24. Daumit GL, Goldberg RW, Anthony C, Dickerson F, Brown CH, Kreyenbuhl J, Wohlheiter K, \& Dixon LB. Physical Activity Patterns in Adults With Severe Mental Illness. Journal of Nervous \& Mental Disease, 2005;193(10):641-6. https:// doi.org/10.1097/01.nmd.0000180737.85895.60 PMID 16208158

25. Gorczynski P, Faulkner G. Exercise therapy for schizophrenia. Schizophrenia Bulletin. 2010;36:665-6. Google Scholar Medline , DOI: 10.1002/14651858.CD004412.pub2.

26. Vancampfort $D$, Probst $M$, Scheewe $T$ et al. Relationships between physical fitness, physical activity, smoking and metabolic and mental health parameters in people with schizophrenia.
Psychiatry Res. 2013;207:25-32. https://doi. org/10.1016/j.psychres.2012.09.026

27. Moxham L, Patterson C, Taylor E, Perlman D, Sumskis S, and Brighton R. A multidisciplinary learning experience contributing to mental health rehabilitation. Disability \& Rehabilitation, 2017;39(1):98-103. https://doi.org/10.3109/09 638288.2016.1146358

28. Pedersen BK, Saltin B. Exercise as medicine - evidence for prescribing exercise as therapy in 26 different chronic diseases. Scandinavian Journal of Medicine and Science Sports, 2015;25:1-72. DOI: 10.1111/sms.12581. https:// doi.org/10.1111/sms.12581

29. Scheewe T.W, Backx F.J, Takken T. et al. "Exercise therapy improves mental and physical health in schizophrenia: a randomized controlled trial," Acta Psychiatrica Scandinavica, 2013;127(6):464-73. DOI: 10.1111/acps. 1202

30. Picton C, Moxham L \& Patterson C. Therapeutic recreation for people with a mental illness is beneficial. Australian Nursing and Midwifery Journal. 2016;23(10):39. PMid:27424455

31. Moxham L, Liersch-Sumskis S, Taylor E, Patterson C \& Brighton R. Preliminary outcomes of a pilot therapeutic recreation camp for people with a mental illness: Links to recovery. Therapeutic Recreation Journal, 2015;49(1):61-75. 